\title{
MST, ALTERMUNDIALISMO, DEMOCRACIA E DIREITOS HUMANOS.
}

Cássio Rodrigues da Silveira

Filósofo. Doutor em História Social pela Universidade Federal de Uberlândia.

cassiofil@yahoo.com.br

resumo: 0 presente artigo visa analisar a tendência, na história do MST (Movimento dos Trabalhadores Rurais Sem Terra), de mundializar as suas demandas e lutas para além da reforma agrária, sem perdê-la de vista, em busca da consolidação de direitos humanos fundamentais por meio do embate com a tendência globalizante do capitalismo neoliberal.

palavras-chave: MST, altermundialismo, democracia, direitos humanos. abstract: The present article tries to analise the tendency, in the history of the MST Movement for the workers without land, to 'mundialize' its demands and fights beyond the agricultural reformation, without losing the latter from sight, to achieve consolidation from fundamental human rights by fighting the globalized tendencies of the neoliberal capitalism.

keywords: MST, altermundialism, democracy, humans rights. 


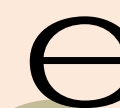

m meus estudos para o doutorado ${ }^{1}$ pude compreender o MST como um movimento tradicional de luta por modificações nas relações no campo brasileiro, ou seja, na busca da realização de uma Reforma A grária em sentido profundo em nosso país. Pudemos perceber que seu surgimento se deveu a uma conjuntura dupla: de um lado, o enfraquecimento da ditadura militar, que permitia a efervescência de diversos movimentos no país, inclusive do nosso objeto; de outro, a acentuação dos problemas históricos vivenciados pela população do campo, com o processo denominado de modernização conservadora.

A percepção de que a terra deveria ser um bem destinado àqueles que dela precisam para viver, enão simplesmenteaos que podem pagar por ela, acompanhou o MST em toda a sua trajetória, e juntamente com a noção de cumprimento da função social, norteou a luta pela Reforma Agrária por parte do movimento, tal como ele a realiza até hoje. Por meio do J ornal Sem Terra nas décadas de 1980 e 1990 e, a partir desta última, também por intermédio dos espaços virtuais, como site, Facebook, Twitter, a luta contra a concentração de terras tem sido feita de forma consistente.

Tal afinco na luta por décadas, com um vigor continuado, exigiu constante renovação nos quadros das lideranças. Pude perceber, também em minha pesquisa, como o sujeito social por nós estudado se preocupa com a formação tanto dos membros da base quanto das futuras lideranças que continuarão a luta, desde 0 momento da mais tenra infância.

Como o movimento tem uma percepção classista, desde sua origem, de orientação nitidamente marxista, por diversas vezes lemos em suas matérias que não deveriam existir grandes expectativas com relação a modificações vindas do Estado. N a visão de Marx, um aparato estatal que esteja conduzindo uma sociedade de economia capitalista sempre deverá se posicional favoravelmente aos interesses das classes economicamente dominantes.

\footnotetext{
1 SILVEIRA. Cássio Rodrigues da. Entre o corte da cerca e a teia da rede: desafios do MST na luta pela reforma agrária no Brasil. Tese (Doutorado em História Social). PPGHIS; INHIS; UFU, Uberlândia, 2015.
} 
Com a eleição de Lula, demonstramos um posicionamento paradoxal do movimento nesse sentido, já que as matérias do período apontavam para a existência de expectativas de modificação significativa das estruturas. Como pudemos acompanhar no desenvolvimento do texto, no entanto, tal esperança foi aos poucos, ao longo dos mandatos petistas, dando lugar a uma frustração perceptível. É desse ponto que começamos a refletir sobre a tendência altermundialista do MST.

\section{sistema capitalista, governo da burguesia?}

Como um movimento de caráter reivindicatório, o Movimento dos Trabal hadores Rurais Sem Terra não pode se furtar, em nenhum momento da sua existência, do trato com as lideranças políticas estabelecidas, fossem elas municipais, estaduais ou federais. É que a desapropriação das áreas que seus membros ocupavam passava pela ação direta dos agentes presentes nas instituições políticas formais. Sempre houve, portanto, uma dependência do movimento com relação ao Estado no que se refere aos avanços nos números de famílias assentadas no país.

No entanto, como já mencionado, o tipo de expectativa que o MST nutriu com relação às possibilidades de que mudanças substanciais pudessem ser efetivadas de fato a partir do aparato estatal foi bastante variável ao longo da sua trajetória. 0 que podemos afirmar, a partir dos textos estudados por nós, pelo menos dos editoriais, de todos os volumes do Jornal Sem Terra, é que a percepção do movimento sempre foi mais pessimista com relação a isso. Destaca-se, em um dos artigos, a fala categórica de que a Reforma A grária no país seria do tamanho do que nosso sujeito social conseguisse realizar, em termos de pressão. Portanto, a crítica e a desconfiança foram, por certo, as posturas mais presentes ao longo de todo este período.

A exceção com relação a isso se deu, de forma muito pontual, quando da eleição, para o seu primeiro mandato, do candidato do PT, Luiz Inácio Lula da Silva. Como um aliado histórico das lutas pela terra, colaborador do Jornal em mais de uma ocasião, indivíduo que reconhecia a importância da Reforma A grária para o desenvolvimento geral da economia brasileira, ele deveria, na percepção do sujeito por nós estudado, levar a cabo a realização de uma modificação profunda da estrutura do campo brasileiro. Esse vinha sendo seu compromisso desde campanhas nas quais ele saíra das urnas derrotado. $\mathrm{N}$ a sua vitória, ficou registrada a comemoração realizada pelos dirigentes do MST em sua principal forma de veiculação de notícias, e se falava mesmo em uma vitória histórica sobre as elites no país, com a chegada ao poder de um governo de esquerda. 
O resultado disso, ao longo do tempo, pôde ser acompanhado por nós, ainda que de forma sucinta, como é possível fazer em uma pesquisa que não tem esse assunto como seu tema central. 0 primeiro mandato de Lula deu continuidade à dinâmica neoliberal de Fernando $\mathrm{H}$ enrique Cardoso, que havia sido ferrenhamente criticado pelo movimento, assim como o segundo. No período da campanha de Dilma Rousseff, nenhuma expectativa persistia mais de que o PT no poder pudesse conduzir às mudanças históricas demandadas pelo movimento. Ao fim de seu primeiro mandato, a avaliação é de que ela teria sido a pior em número de assentamentos em 20 anos, e a nomeação para o ministério da agricultura de uma inimiga declarada do MST, Kátia A breu, infelizmente, desmente a fala do discurso de posse da presidenta, de que ela ouviria com mais atenção os movimentos sociais.

Existe, no entanto, uma relação paradoxal entre movimento e Estado. A dependência com relação às instâncias políticas não pode ser negada. As desapropriações, legalizações dos assentamentos de Reforma Agrária, financiamentos e oferta de assistência técnica vêm envolvendo, durante todas essas décadas, ações de órgãos governamentais. No entanto, apresentando uma ideologia essencialmente marxista, o movimento não deveria demonstrar, em momento al gum, expectativa de mudanças estruturais a partir de ações políticas, advindas de mudanças de lideranças, fossem elas quais fossem. A qui cabem, no entanto, al guns comentários.

Em primeiro lugar, temos consciência, é preciso sempre reiterar, de que não estamos aqui retratando o que pensa o MST, apesar de por vezes a elaboração do texto poder conduzir o leitor a esta confusão. 0 quetentamos assimilar e transmitir são certas representações assimiladas e veiculadas por certos agentes sociais envolvidos com o movimento, acima de tudo suas lideranças e intelectuais que simpatizaram com suas bandeiras de luta. A inda assim, pensando que estamos falando de representações do Jornal Sem Terra sobre os temas elencados como relevantes para nosso artigo, o período de tempo coberto é bastante extenso e, portanto, mudanças poderiam bem ter ocorrido. A lém disso, mesmo pensando na categoria "lideranças", existem regionalidades, diferenças de experiências e de formação que poderiam conduzir à veiculação de concepções bastante diversas ao longo do tempo.

Em segundo lugar, ao pensarmos de forma mais ampliada no "Movimento", penso que a fala de J oão Pedro Stédile com relação à relação do MST com o governo Lula, seja ilustrativa. 
Acho que nós conseguimos manter a nível nacional essa autonomia em relação ao governo Lula. 0 que mudou é que nós estávamos acostumados a ter governos de direita, como na época da ditadura, de centro-direita, como na época de Sarney e do Itamar, e agora nós temos um governo de centro, onde tem gente de direita e gente de esquerda. Então a natureza do governo Lula também é diferente?

Existem tendências dentro do movimento, e elas são, por vezes, muito diferentes. Ele nos fala de uma ala de membros que, a partir de uma concepção mais utilitarista, queria uma proximidade maior com o governo em função das possibilidades de um maior número de benefícios. $N$ ão há razão para julgar como equivocada tal postura, quando sabemos quea lutaé demorada, emuitas vezes cheia de dificuldades. A outra, mais à esquerda, entendendo a gestão petista como representando o centro, e querendo se manter mais à esquerda, exigia um distanciamento maior. Stédile, na minha concepção demonstrando bom senso, dava razão às duas.

Tecemos tais comentários para que o leitor não nos tome como redutores de toda complexidade do MST às representações acessíveis por meio de suas formas de comunicação. Mas a questão que coloco nesse tópico, para que possamos definitivamente adentrar na temática específica do trabalho em curso, é o que me parece ter levado o movimento cada vez mais para fora do Brasil e para causas mais amplas que a Reforma A grária. Excetuando-se a comemoração muito passageira com relação à chegada ao poder do PT, na maioria do tempo nosso sujeito entendeu que em uma economia capitalista, qualquer que fosse o governante, ele representaria os interesses daqueles que detêm o poder econômico. Essa concepção, de cunho marxista, era demonstrada pelos seus membros desde o princípio da sua existência. Darci José A ntunes Maschio, participante da primeira Direção N acional do MST, anotou em seu caderno, em 1984, a seguinte consideração:

${ }^{2}$ TAVARES, Joana. Um novo momento: entrevista com João Pedro Stédile. Jornal Sem Terra, $\mathrm{n}^{\circ} 290$, março de 2009, p. 14. 
Não há diferença entre governo de situação e oposição. Eles se unem em termos de classe dominante. Escolhem 0 melhor caminho para continuar explorando. Estão em partidos diferentes, mas com o mesmo objetivo, queé dominar. Os governos estaduais não têm proposta para os sem-terra. 0 próximo governo federal continuará com a mesma política agrária. ${ }^{3}$

Diante detal convicção, demonstrada de forma consistente, ain da que o MST tivesse que manter relações com o Estado para ratificar as conquistas que ia consolidando, só restava ao movimento, na busca de efetivar de forma definitiva as mudanças que buscava, lutar pela alteração total da ordem vigente e instauração de outra, de cunho socialista, isso é outro mundo. Resta saber, agora, por que meios isso poderia se dar e quais seriam as principais características dessa nova etapa da humanidade que se visa construir.

\section{o altermundialismo}

A primeira coisa importante a sefazer nesse artigo é definir suficientemente o que se entende aqui por altermundialismo. 0 termo é relativamente novo na terminologia dos movimentos sociais, ese refere, na verdade, a uma gama ampla de formas de mobilização contemporâneas. De forma sintética, encaixam-se na nomenclatura todos os grupos que defendem a tese de que um "outro mundo" é possível. Mas aí a questão que se coloca é: outro mundo comparado com qual?Quais os critérios de novidade? Para definir isso, vamos recorrer ao auxílio teórico:

Pode ser dito que a opção pelo Fórum-espaço vem prevalecendo cada vez mais. Mas não há dúvida de que é ainda grande o risco que corre o Fórum de se transformar em movimento. A questão continua presente em todos os debates que se fazem quando da organização de fóruns regionais ou nacionais. $\mathrm{Na}$ Europa especialmente, com o surgimento do "movimento altermundialista", que se propõe a ser uma nova etapa do "movimento antimundialista", é em geral difícil, na linguagem e nos conceitos, caracterizar a diferença que existe entre ele e 0 Fórum. É até possível que o nome "altermundialismo" tenha surgido da proposta do Fórum de se lutar por "outro mundo".

\footnotetext{
${ }^{3}$ SCOLESE, Eduardo. Pioneiros do MST: caminhos e descaminhos de homens e mulheres que criaram o movimento. Rio de Janeiro: Record, 2008, p. 26.

${ }^{4}$ WHITAKHER, Chico. 0 desafio do Fórum Social: um modo de ver. São Paulo: Edições Loyola, 2005, p. 72.
} 
Há uma percepção do autor Chico W hitakher de que o movimento altermundialista é uma nova etapa de outra forma de mobilização, a antimundial ista, eque sua nomenclatura se confunde com a Inauguração do Fórum Social Mundial, que se dá no início do século X X I, no ano de 2001A proposta, como dissemos antes, é de lutar por "outro mundo".

W hitakher também revela uma dificuldade de diferenciar tanto na linguagem quanto nos conceitos, tal movimento do Fórum.E isso podenos oferecer mais uma pista da concepção de funcionamento dessas formas de mobilização social, a partir da própria citação: o Fórum é muito mais um espaço que um movimento. É muito mais uma disposição do que um conteúdo acabado. Muito mais uma forma de mobilizar do que um conjunto de preceitos. Mas será que é possível delimitar um pouco melhor essa novidade? Ela se coloca em relação a que? V ejamos como Michel Lowy nos apresenta a questão:

O movimento altermundialista é sem dúvida o fenômeno mais importante de resistência anti-sistêmica do início do século XXI. Esta vasta nebulosa, esta espécie de "movimento dos movimentos", que se manifesta de forma visível por ocasião dos Fóruns Sociais - regionais ou mundiais - edas grandes manifestações de protesto - contra a OMC, o G8 ou a guerra no Iraque - não corresponde às formas habituais da ação social o política. Grande rede descentralizada, é múltipla, diversa e heterogênea, associando sindicatos operários e movimentos camponeses, ONGs e organizações indígenas, movimentos de mulheres e associações ecológicas, intelectuais e jovens ativistas. Longe de ser uma fraqueza, esta pluralidade é uma das fontes de força, crescimento e expansão do movimento.

Algumas informações que vamos avaliar com calma. Para o autor, 0 fenômeno mais importante de resistência antissistêmica. Portanto, quando falamos detal forma de mobilização, estamos falan do de pessoas que lutam pela modificação de todo o sistema econômico vigente, e que tem, por isso, um caráter altamente revolucionário. Encontraremos suas manifestações mais nítidas, segundo o trecho, nos Fóruns Sociais - outro autor que atribui a eles o potencial de agregação deste ideário - e nas grandes mobilizações de protesto contra algumas instituições ou eventos que, simbolicamente, nos dizem muito.

${ }^{5}$ LOWY, Michel. Negatividade e utopia do movimento altermundialista. Lutas Sociais. 19/20, p. 32. 
A o pensarmos na OMC (Organização Mundial do Comércio) e no G8 (grupo dos países mais desenvolvidos e industrializados do mundo, agora G7, com a exclusão da Rússia, contando com Estados U nidos, A lemanha, Canadá, França, Itália, Japão e Reino Unido), estamos falando de instituições e países que representam a lógica hegemônica do sistema vigente. A guerra do Iraque é uma intervenção considerada um exemplo da prática denominada de Imperialismo. 0 altermundial ismo, portanto, se contrapõe a certa lógica que, sobretudo depois do fim do bloco socialista, se apresenta como último padrão de forma de vida.

U ma palavra é sugestiva: rede. V ivemos em uma sociedade em que as formas de sociabilidade mais horizontalizadas e menos hierarquizadas vêm sendo preferidas às formas mais tradicionais. Essa dinâmica parece ter se inserido na organização dos movimentos. O próprio MST se inseriu na Redea partir de sua página, e interage, nela, com uma série de outros movimentos e organizações. Ao lermos o fragmento, percebemos que esta éa mesma ten dência do Fórum. Descentral ização, multiplicidade, heterogeneidade. A aproximação, como nas redes sociais virtuais, ocorre pelo compartilhamento de interesses ou conteúdos, identidades. Assim coexistem sindicalistas, indígenas, ONGs, movimentos de mulheres e ecológicos. Um grande objetivo compartilhado: a proposta de um "outro mundo". Uma possibilidade. Tal heterogeneidade poderia parecer um ponto fraco para esses sujeitos, já que evidentemente dificulta a consolidação de pautas comuns. 0 fato de virem de lugares tão diversos, com real idades tão distintas, podelevar a queas experiências de uns sejam pouco significativas para os demais que ali se encontram. Principalmente para quem se acostumou a pensar no combate ao sistema capitalista em termos de classe, um espaço tão múltiplo pode parecer pouco produtivo. Para Lowy, no entanto, a "pluralidade é uma das fontes de força, crescimento e expansão do movimento".

Desse modo, podemos entender o altermundialismo como o "movimento dos movimentos". Se assim o fizermos, é muito provável que possamos entender o MST como um desses diversos atores que compõe o movimento maior. No entanto, entre movimento e espaço, parece que seria mais interessante, como propõe W hitakher, compreender o Fórum e outras propostas do tipo como um espaço que potencializa a discussão e posterior ação dos movimentos em seus espaços, com suas práticas, de acordo com as suas demandas especificas. 0 autor nos explica essa dinâmica da seguinte forma:

A ssim, o Fórum proporciona espaços para se construírem alianças em lutas que já se desenvolvem. Não se trata de espaços nos quais os organizadores do Fórum Social Mundial são privilegiados, mas onde forças de resistência e movimentos são projetados como líderes da resistência mundial à globalização. Isso pode incluir não apenas um, mas diversos tipos de resistência, assim como 
múltiplas alianças, seja baseadas em questões específicas, seja alianças de âmbito ideológico mais amplo.6

Os próprios movimentos são líderes de uma resistência mundial à global ização. Existe, como já dissemos acima, um elemento aglutinador das forças de todos esses sujeitos com culturas e histórias tão distintas. É a vontade de estabelecer no planeta novas relações econômicas e humanas. A s alianças, como foi dito, podem e devem ser múltiplas, e suas bases podem ser especificidades de al guns dos grupos queali se encontram como agendas gerais de um universo mais amplo de sujeitos. 0 Fórum, desse modo, é entendido não tanto como "movimento dos movimentos", mas como oportunidade de colocar em interação os sujeitos sociais capazes de, cada um à sua maneira e no seu espaço, a partir da sua luta específica, fazer perguntas e elaborar respostas que nos direcionem para uma realidade diferente da que aí está, cada vez mais global. Existe um inimigo planetário comum, contra o qual esses vários indivíduos entendem quevalea pena lutar. Dentreos lutadores, podem estar homens e mulheres que carregam as tradições do campo, do meio rural, ou, do espaço urbano, em todo o planeta. É o que volta a nos dizer Michel Lowy:

Eis então a nova característica das solidariedades que se tecem dentro e em torno do movimento de resistência à globalização capitalista: o combate por objetivos imediatos comuns a todos - por exemplo, a luta contra a OMC - e a busca comum de novos paradigmas de civilização. Em outros termos: mais do que uma solidariedade com, é uma solidariedade entre organizações diferentes, movimentos sociais ou forças políticas de diversos países ou continentes, que se ajudam e se associam num mesmo combate, diante do mesmo inimigo planetário.

Para dar um exemplo: a rede camponesa internacional Via Campesina reúne movimentos tão diferentes como a Confederação Camponesa francesa, o Movimento dos Sem Terra do Brasil ou os grandes movimentos camponeses na Índia. Essas organizações se ajudam mutuamente, trocam experiências, eatuam juntas contra as políticas neoliberais e contra seus adversários comuns: as multinacionais do agro-negócio, os monopólios dos sementeiros, os fabricantes de transgênicos, os grandes latifundiários. A solidariedade delas é recíproca e, juntas, elas constituem uma das mais potentes, ativas e agitadas componentes do movimento mundial contra a globalização capitalista?

\footnotetext{
${ }^{6}$ WHITAKHER, Chico. 0 desafio do Fórum Social. Op. cit., p. 76.

${ }^{7}$ LOWY, Michel. Negatividade e utopia do movimento altermundialista. Op, cit., p. 33.
} 
O termo usado pelos autores é o mesmo, e permite que possamos seguir para uma conclusão dessenosso tópico do artigo:resistênciaà globalização. Existeum padrão de sociabilidade, que podemos denominar aqui, grosso modo, de capitalismo neoliberal, que incomoda de forma muito parecida a todos os sujeitos que participam das organizações das quais estamos tratando aqui. É contra esse padrão que os diversos indivíduos, dos mais variados movimentos, que seaglutinam em torno da bandeira do altermundialismo, estão lutando, cada um à sua maneira, de acordo com as especificidades dos seus espaços e da sua história. Sua pluralidade ou diversidade, que poderia enfraquecer a causa como um todo, de acordo com Lowy é o motivo de seu crescimento e propagação. Se analisarmos bem a questão, podemos supor uma leitura possível para isso.J áfoi realizada uma luta, muito baseada no marxismo ena noção de classe, contra a hegemonia do capitalismo. Não há como negar os resultados conquistados historicamente pelas experiências do século XX com o chamado "socialismo real", mas parece que o seu sucesso, entendido como a construção de um mundo diferente daquele que existia, não foi efetivado, pelo menos de forma consolidada. Diante disso, partindo da constatação de que o capitalismo é suficientemente fluido para resistir ou absorver investidas dessa natureza, restou talvez, àqueles quequerem lutar contra tal hegemonia, outra alternativa:uma investida tão fluida quanto o próprio sistema. Diversa, plural, em rede, horizontalizada, misturando gêneros, etnias, culturas, anseios.U m movimento polifônico desencadeado a partir de um lugar que, antes de orientálo, proporciona condições de amadurecimento de ideias, estratégias, propostas. A inda é provavelmente muito cedo para se avaliar o alcance e a efetividade de tais ações, mas é possível conceder a tal iniciativa alguma inteligibilidade.

Continuando o diálogo com Michel Lowy, podemos perceber que o exemplo dado pelo autor em seu artigo é exatamente o nosso objeto de estudo. Trata-se de uma ramificação, presa a outra ramificação, presa à teia central. Esclarecendo: entre as lutas das mulheres, dos estudantes, dos negros, das ON Gs, entre tantas outras, existe uma ramificação ondesesituam as lutas dos sujeitos quevêm do espaço rural.N essesentido o autor nos fala de uma rede camponesa internacional chamada $V$ iaCampesina, à qual, como descrito, o MST está vinculado, o que fica explicitado em sua página inicial disponibilizada na internet. Lowy afirma quetal redeaglutina grupos bastantedistintos de indivíduos, como grandes movimentos camponeses na Índia e o MST no Brasil. 0 movimento aqui estudado, portanto, é um ponto em uma complexa rede de organizações de indivíduos que compartilham certa identidade. Tal identificação, como vimos, parece estar muito consolidada nos pontos a serem combatidos pela maioria desses sujeitos, ou seja, no fato de terem uma série de adversários comuns: "as multinacionais do agronegócio, os monopólios dos sementeiros, os fabricantes de transgênicos, os grandes latifundiários". A questão do monopólio das sementes e dos transgênicos será comentada logo na sequência. 
O núcleo camponês no Fórum, no entanto, étambém um ponto de uma teia que aglutina atores dos mais diversos contextos e realidades sociais. Essa parece ser a nova configuração. Como dito acima, éal go incômodo para quem está acostumado com uma organização mais pautada na classe e em pontos de ação mais definidos. Estes, no entanto, parecem não ter apresentado, ao seu tempo, total capacidade de subverter como desejavam a ordem instaurada. A rede dos movimentos denominada de altermundialismo, que aglomera e faz interagirem indivíduos tão diferentes uns dos outros em torno da meta de estabelecer novas formas de relação econômica, de interação social e com a natureza, parece enten der que para combater um capitalismo fluido tal como o contemporâneo, a fluidez tem que ser utilizada como arma. 0 capitalismo foge e se apresenta de formas difusas. A s armas contra ele também terão que ser heterogêneas, intermitentes, al eatórias, dificultando sua assimilação e estabelecendo novas formas de ordenamento não de uma vez, mas gradualmente. Não é uma revolução imediata, mas ela parece estar em curso. 0 MST, ainda que sem perceber em que grau entrava nesse processo com clareza, é hoje um ponto de um ponto da imensa rede antiglobalizante do planeta. De acordo com Chico W hitakher, ponto importante em um processo que se desenvolve de acordo com seu próprio ritmo. Fechemos esta parte da análise com uma última fala deste autor:

O esquema de um "outro mundo" está emergindo não somente das interações queacontecem no Fórum Social Mundial, mas por meio dos debates, discussões e, mais importanteque tudo, das lutas pelo mundo afora. O FSM somente cria a oportunidade de enriquecimento desses debates, de apresentação de grandenúmero de perspectivas - algumas competitivas, outras complementares. E não é só isso. Ele está propiciando a possibilidade de construir estratégias comuns para as lutas, está potencializando energias que se encontram. Essas sinergias não englobam todos que participam dos FSM, eem muitos casos nem mesmo a maioria. Mas elas estão sendo construídas.

O Fórum canaliza as energias, potencializa os debates, oferece os espaços, permite que experiências de resistências contra a opressão e de lutas sejam compartilhadas. Isso faz com que ações concretas, posteriormente, possam ser tomadas pelos participantes, que levam os direcionamentos e as novas vivências para seus espaços de origem. Levam, acima de tudo, esperança de al go novo. Com o passar do tempo, a luta solitária de um movimento só, às vezes sem grandes conquistas, pode ir conduzindo seus participantes para a apatia.

${ }^{8}$ WHITAKHER, Chico. 0 desafio do Fórum Social. Op. cit., p. 76. 
Não é fácil batalhar sem expectativa de sucesso. 0 encontro com outras formas de fazer e com relatos de superação pode, com certeza, ser de grande valia no retorno à batalha. Parece que a teia de movimentos demonstra tal capacidade. 0 autor deixa claro que é possível quenem todos os participantes sejam atingidos pela sinergia do ambiente ou, sequer a maioria. Mas, ao mesmo tempo, é otimista com relação à possibilidade de aqueles que o são realizarem transformações a partir dali nos espaços dos quais fazem parte. É uma nova forma de se entender a mobilização, para a qual nos conduziu o estudo do MST. Vamos tentar perceber agora o que 0 conduziu até aí e o que ele realmente compartilha com o altermundialismo.

\section{um campesinato global}

O sujeito por nós estudado se apresentava, desde o primeiro número do Jornal Sem Terra, ainda na sua fase de Boletim Informativo, em 1981, como um sujeito plural, diversificado. Lembremo-nos de que o MST ainda não existia oficial mente nesse momento, mas que a ocu pação da Encruzilhada N atalino, desse ano, éum evento simbólico e em termos de experiência importante para o processo do seu surgimento, um Mito Fundador. A li se encontravam cerca de 500 famílias, entre as quais existiam pequenos arrendatários, posseiros da área indígena, peões, diaristas, meeiros, agregados, parceiros. As situações de origem, portanto, eram significativamente distintas, mas tais indivíduos conseguiram se organizar em uma luta que só teve seu desenrolar definitivo na segunda metade de 1983.É claro que al guma rotatividade deve ter existido entre aqueles que iniciaram e os que viram 0 término do processo, mas em termos gerais a maioria permaneceu, apesar das diferenças e, talvez, auxiliados por elas.

Esta é a primeira característica que podemos encontrar na figura do camponês tal como o estudamos aqui.A pesar defazer parte de uma estrutura social que remonta ao passado, em função da lida com a terra, na contraposição arbitrária campo/cidade, na qual o primeiro lembra o arcaico e a segunda o moderno, tais sujeitos, quando se colocam juntos, sobretudo em função de uma causa coletiva, demonstram uma capacidade imensa de adaptação a circunstâncias complexas, grande parte das vezes inóspitas. A o pensarmos, desse modo, na sua identidade, é claro que temos que inserir na compreensão, em primeiro lugar, os vínculos com o espaço agrário, ou um retorno a ele ou uma busca de atingi-lo. No entanto, essa capacidade de enfrentar o novo e a diversidade no momento dos conflitos também é uma característica que, em geral, precisa ser ressaltada, sobretudo nesse camponês do movimento, do qual tratamos aqui. 
N esse sentido, essa capacidade de se vincular a um campo que nem conhece faz dos outros camponeses, aqueles que foram se unindo ao MST durante a sua trajetória, figuras interessantes de serem estudadas, sobretudo, no que diz respeito aos fatores motivadores para essas suas opções. É óbvio que o fato de viverem em condições muitas vezes degradantes nos auxilia a entender porque muitos desses indivíduos projetam suas esperanças em algo que nem conhecem, e, por vezes, difícil de conseguir. A inda assim, essa capacidade de acreditar em outra realidade, a ela retornando ou conhecendo-a a partir da luta, é uma das marcas do nosso sujeito. De acordo com A rmando BartraV ergés, o camponês

aparece primeiro como evidência social; como protagonista de movimentos reivindicatórios, como projeto e utopia, como socialização rural, como cultura, como discurso, como imaginário coletivo, como nostal gia. Sujeito de todos os paradoxos, na luta que liberta diversos tipos de demandantes de terra - que apesar de serem camponeses, não cultivam para si e, em certas ocasiões, vivem na cidade - 0 camponês surge como vontade de ser, como projeto, como carência e aspiração?

É uma identidade complexa, como podemos ver, e que, como as demais, também deve ser entendida pela ausência, pelo que lhe falta, pelas carências, que são justamente o que faz com que seja o que é. Desse modo, entre os sujeitos distintos que iniciaram as ocupações, primeiro no fim da década de 1970, chegando à Encruzilhada Natalino, e perpassando todo o caminho do Movimento dos Trabalhadores Rurais Sem Terra, apesar de todas as diferenças de origem, de experiências, de vivências, de culturas, sempre existiu uma demanda, fosse de retorno ou de chegada, pela inserção no espaço rural, entendido como uma forma de produzir uma vida digna para eles e para os seus.

Como ocupantes de um espaço no qual "não deveriam estar", em função de uma documentação que garante a propriedade a um outro, eles se tornam, como o próprio trecho diz, uma "evidência social". Visíveis para quem passa elou tornados assim pelos meios de comunicação regionais e por vezes nacionais, são unificados pelas representações construídas a seu respeito, ora demonizados, ora vitimizados, tornandoos, na maioria das vezes, uma massa homogênea, de marginais ou de coitados.

\footnotetext{
9 BARTRA, Armando. Os novos camponeses: leituras a partir do México profundo. São Paulo: Cultura Acadêmica; Cátedra Unesco de Educação do Campo e Desenvolvimento Rural, 2011, p. 68.
} 
De todo modo, se fazem notar e, como sabemos, tal fato sempre se tratou de uma arma no caso do MST para chamar a atenção da opinião pública e pressionar as autoridades instituídas no atendimento de suas demandas.

Por meio do Jornal Sem Terra, durante mais de trinta anos, o MST tem apresentado um "discurso", como podemos ver até aqui, coerente com certas concepções ideológicas adquiridas e defendidas desde muito cedo; aprendeu e desenvolveu formas de sociabilidade e de produção que também são transmitidas pelos seus veículos. A produção cultural, por meio das músicas, poemas, teatro, quando pensamos no movimento como um todo, é bastante considerável. É claro que cada um desses aspectos, para ser mais bem detalhado, demandaria uma pesquisa específica, o que não nos é possível no momento.

Existe, por último, uma concepção imaginária e até mesmo, como o próprio trecho ainda afirma, nostálgica da figura do camponês. Esse, talvez, seja um dos motivos de visões pouco simpáticas com relação aos membros dos movimentos. Trata-se de uma percepção de que a um homem do campo cabem certas práticas, ao passo que outras não, o que tenderia a engessar sua figura no passado, abolindo da sua vivência os confortos que podem ser garantidos pelas novas tecnologias, ou mesmo uma percepção que vise o sucesso financeiro por parte do assentado. Todas essas é preciso que fique claro, são construções sociais. Esses indivíduos, na produção da sua identidade na luta cotidiana, por certo têm que lidar com todas, elas, filtra-las e, no fim das contas, avaliar o que vale a pena levar para si. N o entanto, o que colocou as nossas 500 famílias juntas, em 1981, na Encruzilhada Natalino, foi essencialmente a "vontade de ser", o "projeto", a "carência" e a "aspiração". Aliás, de acordo com o mesmo Bartra, não é fácil ser camponês depois de estabelecida a modernidade. De acordo com ele

os camponeses são anacrônicos eutópicos, uma classeabandonada pela economia e pela história, condenada à morte em todos os tribunais da modernidade. As revoluções burguesas deveriam enterrálos juntamente com o feudalismo; o desenvolvimento capitalista tende a fragmentálos em empresários agrícolas e proletários do campo e o socialismo procura combatelos por considerálos como a sementeira de uma desprezível burguesia rural..$^{10}$

10 Idem. 
De fato, se pensamos em todo o processo vivido no Brasil de modernização conservadora, percebemos que não houve uma opção política, boa parte do tempo, de se manter as condições para que este tipo de sujeito continuasse a existir. Os incentivos governamentais foram, sobretudo, no período de surgimento do MST, para o chamado A gronegócio. A questão da integração como empresário agrícola é um pouco mais complexa, pois os níveis em que isso acontece são muito variáveis. No Brasil. o debate se encontra, basicamente, em torno do conceito de "agricultura familiar", pois esta é exatamente a categoria que está inserida nas possibilidades de financiamento por parte do próprio Estado, por meio do Pronaf (Programa de fortalecimento da agricultura familiar, criado em 1996, no período do governo Fernando Henrique Cardoso).

De acordo com Bernardo Mançano Fernandes, uma das marcas que diferenciam a noção de camponês daquela que enquadra a agricultura familiar é o fato de que essa última é marcada pela "integração ao mercado, o papel determinante do Estado no desenvolvimento de políticas públicas e a incorporação de tecnologias "11. Como a questão do financiamento é algo de extrema importância no atual estágio do campo brasileiro, se existe a possibilidade de consegui-lo se enquadrando em uma categoria, é compreensível que parte considerável dos sujeitos que ocupam o espaço agrário o façam. Não penso que isso seja sequer condenável. No entanto, se aceitamos realmente a diferenciação, o que segue, de acordo com o próprio autor, é que para o camponês

ou ele se metamorfoseiaem agricultor familiar e se integra ou se mantém como ele mesmo e sedesintegra. N estes referenciais não há futuro, porque não há perspectiva dessesujeito continuar sendo camponês. Na verdade, ele é visto como um estorvopara os que veem sua desintegração, consideran do que do campesinato podem surgir o capitalista e o proletário. Igualmente é visto como um estorvopara os que veem sua integração, porque o camponês desenvolve, também, aluta contra o capital. ${ }^{12}$

Mançano segue o mesmo raciocínio de Bartra no sentido de perceber a figura do camponês como alguém que não é bem quisto pelo processo de modernização capitalista. Como as formas de financiamento são dirigidas essencialmente a um sujeito, se o camponês não entra nessa categorização sua sobrevivência se torna

\footnotetext{
11 FERNANDES, Bernardo Mançano. A formação do MST no Brasil. Petrópolis: Vozes, 2000, p. 3.

12 Idem, Ibidem, p. 4.
} 
difícil. A o adentrar, de acordo com a percepção do autor, ele perde algo da sua identidade. A presentamos o trecho só para demonstrar como às vezes, senão boa parte delas, o intelectual encontra problemas onde os próprios sujeitos sociais não 0 veem. Essa diferenciação entre os termos, que o autor entende como relevante, em nenhum momento é encarada realmente como algo essencial pelo próprio J ornal Sem Terra, nossa fonte de pesquisa central.Durante todo o tempo existe um embate muito claro que coloca, de um lado, o agronegócio e do outro, as agriculturas familiar e camponesa. V ejamos um trecho:

No início de março, a Via Campesina e a A ssociação Brasileira de Reforma A grária (A BRA) elaboraram um balanço das ações do governo Lula nestes três anos. A avaliação foi negativa: para dez medidas a favor da agricultura familiar, houveram trinta que priorizaram o modelo de agronegócio.13

Em outras matérias ${ }^{14}$, que não teremos tempo de analisar aqui, o MST coloca "agricultura familiar" e "camponesa" como termos sinônimos, não problematizando a diferença de nível de vínculos com o mercado ou o Estado entre as duas. Reiterando o que foi dito acima a partir da citação, o que se percebe é o confronto entre as agriculturas familiar e camponesa, de um lado, e o agronegócio, do outro. Aí se encontra o conflito. Mesmo porque, já que o governo federal tem um programa de financiamento para o pequeno agricultor que está voltado para a sua forma familiar, nada mais racional do que os assentados se adequarem a esse enquadramento, na busca de financiamentos para as suas lavouras. 0 debate, portanto, pelo menos quando pensamos nas representações assimiladas nos meios de comunicação do Movimento dos Trabalhadores Rurais Sem Terra, se realiza no ainda baixo percentual orçamentário voltado para financiar o pequeno agricultor no país, quan do comparado àquele destinado aos agronegócios, eem alguns momentos, a queixa se estende até sobre a quantidade de burocracia enfrentada pelos que mais precisam.

Desse modo, percebemos que a identidade do camponês (esse termo sim é utilizado) efetivada pelo MST, desde o seu início é, sobretudo, estabelecida no confronto com a noção de latifúndio/agronegócio. Os percal ços para a sobrevivência desse sujeito com os processos de modernização, apresentados tanto por Bartra

${ }^{13}$ DIREÇÃO NACIONAL do MST. A reforma agrária e a disputa de modelos. Jornal Sem Terra, n. ${ }^{\circ} 260$, março de 2006, p. 2.

${ }^{14}$ A MOBILIZAÇÃO POPULAR dos sem-terra em 25 de julho. Jornal Sem Terra, n. 265, agosto de 2006. 
quanto por Mançano, nos parece ser admitido pelo movimento quando reclama, constantemente, das dificuldades com relação às prioridades de auxílio do Estado para o pequeno agricultor em geral. No entanto, apesar de, em geral, tais sujeitos sociais nos remeteram à imagem de figuras vinculadas ao local, à terra, ao solo, 0 movimento foi, muito rapidamente, ao mesmo tempo em que se tornava nacional, se internacionalizando.

A nacionalização ocorre em 1985, como vimos no capítulo anterior. A té 1984, o que existia era um Regional Sul. Com o espalhamento pelo país, no entanto, lentamente tem início a internacionalização. Já no ano de 1985 vamos encontrar números com o apoio a agricultores na N icarágua e uma entrevista com Sergio Ramirez Mercado, com o título "A paz na América Central depende somente dos EUA".15 O número de dezembro desse mesmo ano também aparece com reportagem internacional, esta sobre o Equador, de nome "Campesinos lutam por uma verdadeira Reforma Agrária no Equador". Nela percebemos o desejo do movimento de estabelecer vínculos com a A mérica Latina e de aprender com outras experiências, tanto positivas quanto negativas. $V$ ejamos:

No momento em que o governo brasileiro lança um plano de Reforma A grária, émuito oportuno conhecer a experiência vivida por outros povos (sofridos) desse imenso continente latinoamericano. No Equador, um dos menores países da A mérica Latina, foram feitas duas leis de Reforma A grária (num período de nove anos 64/73) que pouco ou quase nada mudaram a situação de miséria e de abandono dos camponeses e dos índios. Como pode isto acontecer? ${ }^{16}$

A nacionalização vem junto com a internacionalização. Esta, na reportagem, é justificada na busca da experiência em um momento em que no Brasil se passa por um processo que exige a reflexão. No entanto, podemos assimilar na matéria o que gera a verdadeira identidade latino-americana entre os sujeitos que lutam: são gente sofrida. O capitalismo compromete os laços de confiança das relações tradicionais em função da geração de um processo de individualização constante. Os movimentos que estudamos aqui, comoapontamos, tendem a criar novos laços a partir das necessidades, dos sofrimentos, das agruras. A s dificuldades globalizadas, junto com a oferta cada vez maior de comunicação, potencializam a organização dos

15 Jornal Sem Terra, n. ${ }^{\circ}$ 48, Out./Nov. 1985.

16 LAVORATI, Liliana. Campesinos lutam por uma verdadeira Reforma Agrária no Equador. Jornal Sem Terra, n. ${ }^{\circ} 49$, Dez./1985, p. 8-9. 
despossuídos. E é preciso atentar para o fato de que em 1985 nós não tínhamos as possibilidades de difusão deinformações ede contato com outras pessoas quetemos hoje. Elas eram muito escassas. A inda assim a mobilização acontecia.

O que estamos percebendo aqui é que a solidariedade em torno de lutas compartilhadas é a base do altermundialismo. São novas relações de confiança moldadas em torno das necessidades. Debaixo da lona preta, passando por dificuldades no cotidiano, parece que esses sujeitos tinham uma percepção muito clara de que era preciso mobilizar aqueles que tinham causas parecidas. De acordo com Milton Santos, essa é uma tendência compreensível. Segundo o autor,

como a surpresa se dá como rotina, a riqueza dos "não-posstridores"
é a prontidão dos sentidos. É com essa força que eles se eximem
da contrafinalidade e ao lado da busca de bens materiais finitos
cultivam a procura de bens infinitos como a solidariedade e a
liberdade: estes, quanto mais se distribuem, mais aumentam. ${ }^{17}$

O "não possuir" se torna uma riqueza, no sentido do texto, porque é o fator aglutinante que potencializa a mobilização dos sujeitos por mudanças efetivas. $\mathrm{E}$ a partir da luta pelo que é mais urgente, no caso do MST, a terra, ocorre a ampliação para causas mais abstratas, chamadas de "bens infinitos" por Santos, que são a solidariedade, a liberdade, a fraternidade. É uma globalização solidária contra a globalização individualizante. Estaúltima éuma ten dência do capitalismo avançado, com um consumo cada vez mais individualizado, laços de confiança tradicionais cada vez menos significativos. A quela, defendida pelos movimentos, busca a mudança geral dessa lógica em razão, como vimos acima, de um mundo com relações diferentes em todos os níveis: econômico, ecológico, humano.

Em 1994, um passo importantíssimo rumo a uma organização mais ampla dos camponeses: o I Congresso Latino-A mericano de Organizações do Campo, em Lima, no Peru. Deacordo com a matéria representantes de 20 países seencontravam na ocasião, 17 da A mérica Latina e 3 da Europa. Outros movimentos brasileiros também enviaram representantes, tais como o Departamento Rural da CUT, a CPT e o Movimento de Mulheres Trabal hadoras Rurais. A inda segundo a publicação, 0

\footnotetext{
17 SANTOS, Milton. Por uma outra globalização: do pensamento único à consciência universal. Rio de Janeiro: Record, 2007, p. 130.
} 
evento teve o objetivo de intercambiar experiências entre nossas organizações e buscar formas de coordenação de ações conjuntas, firmando as raízes de uma organização que procurará encontrar alternativas que se contraponham e resistam às políticas neoliberais que vem deixando rastros de miséria e violência por todo o continente. ${ }^{18}$

Desse congresso surgia, formalmente, a Coordenadoria Latino-americana de Organizações do Campo (CLOC), hoje também com sua página na internet, contando com mais de 80 organizações de 18 países da A mérica Latina e do Caribe. De acordo com a informação do próprio site,

1994 foi um ano marcante para os movimentos populares na região, sinais de recuperação das lutas sociais, particularmente no campo, contra as políticas neoliberais. Ele começa com o levante zapatista em Chiapas, no México, e em seguida, registra o segundo levante indígena no Equador, as marchas dos cocaleros na Bolívia, mobilizações para a reforma agrária no Paraguai, Guatemala e Brasil, entre outros eventos. ${ }^{19}$

Então estava formada a rede latina dos movimentos campesinos. Claro que ainda não existia página, nem do MST, nem da CLOC.N o momento do I Congresso provavelmente ninguém tinha muito claro onde tais mobilizações iriam parar. No entanto, a vontade de lutar parece que era o ponto marcante, e existia um ponto de convergência de tantos sujeitos sociais distintos, só o Brasil com 51 delegados de 6 movimentos diferentes. Existia um modelo que se espalhava pelo continente e que deixava rastros de miséria e de violência por onde passava.

Trata-se de um senso de unidade imenso, ao pensarmos nesse número de sujeitos, de tantos países, com várias histórias e experiências diferentes. E 0 interessante é que, aparentemente, não se quer chegar, a partir da organização, à homogeneização dos sujeitos, dos pontos de pauta ou das estratégias de solução. A busca é de estabelecer uma coordenação de ações, a partir do intercâmbio de experiências, para o combate, nas regionalidades, de uma forma de gestão política que, na concepção das lideranças camponesas, é injusta. Mas pelo trecho da página

\footnotetext{
18 I Congresso Latino-Americano de Organizações do Campo reafirma unidade na luta. Jornal Sem Terra, $\mathrm{n}^{\circ} 134$, março de 1994, p. 14.

19 Disponível em http://www.cloc-viacampesina.net/es/quienes-somos, acessado em 15/01/2015.
} 
da CLOC podemos perceber a diversidade dos indivíduos. Mas a questão que pode incomodar alguns, inclusive a este que realiza o estudo, é sobre as estratégias de ordenamento de sujeitos tão distintos. Toda essa diversidade não atrapal ha? N ão seria mais fácil homogeneizar para organizar? A rmando Bartra, ao nos descrever o camponês mexicano, afirma que eles gostam de viver apartados, dispersos, espalhados, diversos, plurais. $N$ as suas palavras:

Pluralidade extrema, que talvez tenha representado um entrave e vergonha quando a moeda era a unanimidade do uniforme, mas privilégio e fortuna quando se reconhece a virtude que vive nas diferenças. Então, para que os camponeses se construam como sujeitos unitários, inventem-se como classe, énecessário tecer um barroquíssimo tapete de incontáveis fios e múltiplos teares; em rigor, trata-se de costurar a unidade na diversidade. ${ }^{20}$

Mais de 80 organizações, 18 países. A CLOC é um tapete bastante colorido. Só do Brasil, no Congresso de fundação, mulheres camponesas, atingidos por barragens, o braço católico da luta pela terra, o braço sindical. Ao colocarmos representantes dessas quatro tendências para decidir um assunto qualquer, sabemos que não será algo fácil. Divergências de ideias entre sujeitos podem levar a demandas demoradas. Mas parece quenão éesse o ponto de vista adotado por quem se envolve nesse tipo de empreitada. 0 que se nota na matéria do J ornal Sem Terra sobre o I Congresso é que existe uma busca por alternativas para a realização de ações coordenadas. A meta é 0 aprendizado com experiências tão distintas de sujeitos tão diferentes, para, a partir daí, realizar a intervenção na realidade. Há, portanto, uma val orização da pluralidade que, como afirma Bartra, é um privilégio quando se reconhece a "virtude que vive nas diferenças".

Se essas experiências continentais são enriquecedoras, a ampliação para o conhecimento de experiência de outros continentes, evidentemente, o éainda mais. O vínculo com a CLOC foi a ponte para conduzir o MST a uma parceira ainda maior:aV iaCampesina. $V$ ejamos como estenosso sujeito internacional seapresenta em sua página:

20BARTRA, Armando. Os novos camponeses. Op. cit., p. 321. 
A Via Campesina éum movimento internacional que reúne milhões de camponeses, agricultores de pequeno e médio porte, sem-terra, mulheres agricultoras, povos indígenas, migrantes e trabahadores agrícolas de todo o mundo. Ele defende a agricultura sustentável em pequena escala, como forma de promover ajustiça social edignidadeEla se opõe fortemente a agricultura dirigida pelas corporações e empresas transnacionais queestão destruindo as pessoas ea natureza. ${ }^{21}$

O número é bastante considerável, pois a página fala de milhões de indivíduos espalhados pelo planeta fazendo parte do movimento. É possível, no entanto, relativizar um pouco tais números. $\mathrm{A} V \mathrm{~V}$ ia Campesina é um movimento de movimentos de camponeses, de acordo com o que se pode perceber. Os números que apresenta, obviamente, são aqueles que resultam da soma dos participantes dos movimentos que participam dela. Não é possível afirmar que cada membro de organização ligada à $V$ ia no mundo saiba desse fato ou saiba o que ela significa e quais são suas ideias. $N$ o entanto, o vínculo, teoricamente, existe. $A$ gama de sujeitos presentes é tão ou mais plural que aquela que já havíamos analisado na CLOC. No entanto, existem pontos de pauta muito claros e objetivos que podem aglutinar indivíduos tão distintos. A luta da Via é a favor de uma "agricultura sustentável em pequena escala, como forma de promover a justiça social e dignidade"

Com uma causa como esta, sabemos que o MST, nosso objeto de pesquisa, pode participar da luta sem nenhum tipo de restrição. Dignidade, justiça social, sustentabilidade e agricultura em pequena escala são pontos de luta do nosso movimento desde a sua origem. A Via é contra "a agricultura dirigida pelas corporações e empresas transnacionais que estão destruindo as pessoas e a natureza". Já vimos acima no texto que o agronegócio é considerado o grande inimigo na formação da identidade do Movimento dos Trabalhadores Rurais Sem Terra, também no Brasil. Falaremos sobre a questão da sustentabilidade logo em seguida, mas podemos adiantar que o MST sempre esteve preocupado com isso também. Desse modo, em todo o planeta, os movimentos que compartilham tais ideias com aquele que estudamos aqui, pode também ser um membro da V ia Campesina.

Na página do movimento, quanto ao número de movimentos, constam 164 organizações em 73 países de quatro continentes. Mais do que os pontos de pauta comuns, tanto objetivos a serem al cançados quanto elementos a serem combatidos, a $V$ ia acredita que al guns sentimentos unam seus membros em todo o planeta. Em outro trecho da página podemos ler:

21 Disponível em http://viacampesina.org/en/index.php/organisation-mainmenu-44/what-is-la-viacampesina-mainmenu-45, acessado em 15/01/2015. 
A V ia Campesina é construída sobre um forte senso de unidadee solidariedade entre os pequenos e médios produtores agrícolas do Norte e do Sul. O principal objetivo do movimento é realizar a soberania alimentar e parar o processo neoliberal destrutivo. Baseizse a convicção de que os pequenos agricultores, incluindo pequenos pescadores, os pastores e os povos indígenas, que representam quase metade da população do mundo, são capazes de produzir alimentos para as suas comunidades e alimentar 0 mundo de forma sustentável e saudável. ${ }^{22}$

N ovamente as palavras de ordem que lemos acima: pela sustentabilidade, contra o neoliberalismo. Mas a questão posta é que, para o movimento, existe um "senso de unidade e solidariedade" entre os camponeses do norte e do sul. É interessante que sujeitos que não se conheçam, possivelmente nem saibam onde fica a cidade em que vive o outro, possam se solidarizar com a condição dos outros. Pode ser que estejamos tratando somente de palavras, e que tal sentimento sequer exista. Eu, no entanto, não faço essa aposta. As conquistas do MST no Brasil se deveram a um engajamento considerável de seus participantes, e isso é difícil de refutar. Quando lemos notícias de mobilizações, ou assistimos a discussões sobre sustentabilidade, agrotóxicos, transgênicos, geralmente o nome da Via Campesina pode ser encontrado representado por debatedores. Esses sujeitos sociais se encontram no campo de luta por uma realidade diferente, e estão nisso porque vislumbram um mundo distinto do que aí está, com uma nova relação com a natureza, dos homens uns com os outros, com os alimentos. Querer que isso se estenda por todo o planeta e atinja todos os indivíduos é, a meu ver, ser solidário. E isso porque o espalhamento das relações buscadas por esses movimentos significaria, pelo menos na sua utopia, maiores níveis de justiça social.

Desse modo, com alguns pontos de pauta comuns bastante simples, a sustentabilidade, a agricultura realizada em pequenas extensões de terra, a justiça social, o combate ao agronegócio e ao seu grande difusor no planeta, o modelo neoliberal a rede de movimentos campesinos vai costurando a "unidade na diversidade". Não nos esqueçamos de que isso só é possível porque esses sujeitos sociais, ao longo de suas lutas, no caso do MST debaixo da lona preta, em função das carências e dos sofrimentos, desenvolvem, como nos afirmava Milton Santos, um sentimento muito forte de solidariedade, de pertencimento a uma causa comum.

22 Idem, ibidem. 
Em tempos de hiperindividualização, é um mérito considerável dessas formas de organização gerar tal forma de ver o mundo, ainda que em níveis tão distintos entre os diferentes sujeitos, obviamente. Foi assim que o nosso sujeito social, tão diversificado em um país com dimensões continentais, vivendo cotidianamente o desafio de construir uma identidade agrária brasileira, com uma ideologia formada para a luta que ele considera necessária, se vinculou aos poucos a outras organizações latino-americanas, ajudando a fundar uma organização maior, para finalmente ingressar na V ia Campesina e estabelecer-se na Rede camponesa planetária que, ao se ligar ao Fórum Social Mundial, articula forças distintas do mundo todo na luta por "um outro mundo possível"

\section{mst, neoliberalismo e imperialismo}

Como visto acima, um dos pontos de pauta comum tanto do braço latinoamericano dos camponeses quanto do mundial é a luta contra o chamado neoliberalismo. Tal forma de conduzir a economia por parte do Estado, fazendo com que este se afaste de suas obrigações sociais, abrindo mais espaço para a sociedade civil organizada e, sobretudo, para o mercado, sempre foi uma iniciativa dos países centrais e das grandes organizações que representam o capital internacional. Portanto, a essa imposição de tal forma de gestão aos demais países, que são dependentes economicamente tanto das nações mais abastadas quanto de instituições quanto a Organização Mundial do Comércio e o Fundo Monetário Internacional, é chamada de imperialismo. A luta contra a forma de gestão por parte dos movimentos sociais implica a luta contra o seu espalhamento. N este tópico, portanto, comentaremos como, ao longo da existência do Jornal Sem Terra, foram tratados os temas do neoliberalismo e do imperialismo.

No ano de 1988 o JST criou uma sessão chamada A mérica Latina. Em fevereiro ela veio com uma matéria de nome "Unir a América Latina", demonstrando a percepção da necessidade, por parte do movimento, de trocas de experiências sobre as lutas que os sujeitos sociais estavam travando nos diversos países do continente. $\mathrm{Na}$ edição de janeiro/fevereiro de 1990 o J ornal trouxe, em matéria da sessão de nome "Patrão imperialista, atinge Panamá" a seguinte afirmação:

A agressão do imperialismo norteamericano contra o Panamá, em dezembro passado, éa quarta de suas intervenções na A mérica Latina nos últimos dez anos, sem contar o ataque permanentea Cuba. ${ }^{23}$

${ }^{23}$ Patrão Imperialista, agride Panamá. Jornal Sem Terra, n. ${ }^{\circ}$ 91. Jan./Fev./1990. p. 21. 
Seis anos antes da fundação da CLOC, uma rede de movimentos do campo da A mérica Latina, e bem antes, também, do início das reuniões do Fórum Social Mundial, em 2001, o movimento já se manifestava, no âmbito latino-americano, contra certa lógica que o incomodava. Faz parte, portanto, da sua dinâmica, como vimos desde 1985, com as primeiras matérias sobre nosso continente, a tendência de ampliação da luta para os ambientes que Ihe são solidários. É claro que o desenvolvimento de meios técnicos que facilitassem tal postura foi determinante para 0 alcance desse tipo de ações. No entanto, desde que o MST se nacionalizou, vemos esses sujeitos em uma busca de aglutinar experiências e ampliar resultados.

Como vimos anteriormente, apesar delutar por reformas no sistemajurídico e político do país, buscando a propriedade da terra para seus participantes, é nítido, nesse exato período do movimento o discurso mais forte no sentido de revolucionar. É de 1989 uma das falas sobre o socialismo como a grande meta do movimento. Portanto, sem nos alongar desnecessariamente em detalhes, poderemos acompanhar a partir deste momento uma ten dência cada vez maior das publicações ao combate à lógica capital ista internacional, inclusive com a publicação de textos de intelectuais. Em setembro de 1995, leremos:

O capitalismo é o vencedor mais estúpido que a história já conheceu. 0 Ocidentenão refletiu com autocrítica a respeito de sua vitória sobre o socialismo real. Em vez disso, tentou declarar como modelo de sua hegemonia a ideologia do mercado total, que nunca foi real em sua história, fazendo-a remédio para todos os males e tentando exportála a todo custo para todas as regiões do mundo. ${ }^{24}$

$\mathrm{O}$ autor é Robert Kurz, apresentado na matéria como sociólogo alemão. $\mathrm{Na}$ verdade, sua formação inicial é em filosofia, e seu livro mais conhecido no Brasil seria "O colapso da modernização" ${ }^{25}$. Temos, portanto, um texto com uma boa fundamentação teórica, que trata exatamente da consolidação da hegemonia do discurso capitalista de mercado, de forma gl obalizada. O MST, como sempre, desde que se enten de como movimento, mantém-se na crítica ferrenha a esse modelo. No trecho, uma chamada de reflexão sobre essa pretensa vitória da economia de mercado sobre o socialismo, com a fragmentação desse sistema nos países que 0 haviam adotado durante parte significativa do século XX.

\footnotetext{
${ }^{24}$ Robert Kurz. A estupidez do neoliberalismo. Jornal Sem Terra. n. ${ }^{\circ}$ 151. Set./1995. p. 3.

${ }^{25}$ KURZ, Robert. O colapso da modernização: da derrocada do socialismo de caserna à crise da economia mundial. Rio de Janeiro: Editora Paz e Terra, 1992.
} 
A tentativa de exportação a todo custo de tal modelo para "todas as regiões do mundo" é o que estamos denominando nesse tópico de imperialismo.

Mas o MST, que como vimos manteve uma parceria com intelectuais para o embasamento de seus membros desde muito cedo, publica tal texto não só para criticar o autoritarismo presente na busca da imposição de um modelo único para espaços tão diferentes. A diante no texto 0 autor nos fala da ausência de viabilidade do que está se espal han do e da necessidade da criação de alternativas. V ejamos mais um trecho:

\begin{abstract}
Se o socialismo era uma ideia nobre, porém não feito para o homem real, a economia de mercado globalizada nem chega a ser nobre. Não funciona e não é nem um pouco viável para a grande maioria. Mas esta não permanecerá tanto tempo, pois o neoliberalismo nada mais é que a ideologia da moda conveniente para a estupidez dos capitalistas num momento histórico de susto. A humanidade precisa inventar algo fundamentalmente novo. A cirurgia neoliberal pode ter lógica, mas levará o paciente à morte ${ }^{26}$
\end{abstract}

Não há nobreza na economia de mercado globalizada. Essa é, no fundo, a mensagem que se quer deixar clara a partir da matéria. Nem nos países mais desenvolvidos, nos quais os governantes optaram pela adoção do modelo neoliberal, conseguiram de fato resolver seus problemas de acordo com as promessas feitas às suas populações. 0 espalhamento de um modelo tão gerador de desigualdades para espaços já marcados por ela, evidentemente, tenderia a levar a resultados ainda mais catastróficos, e era o que acontecia. 0 autor adiantava, no entanto, que tal dinâmica do capital não duraria por muito tempo, pois quelevaria aqueles queautilizavam àmorte, penso que em todos os sentidos, econômico e físico no caso dos indivíduos atingidos pela situação de indigência por um sistema que causa a desigual dade extrema.

No entanto, o convite: "a humanidade precisa inventar algo fundamentalmente novo". Já em 1995, recém-vinculado às organizações internacionais que vimos acima, a CLOC que ele ajudou a fundar, o MST publica um texto em seu J ornal que convoca seus membros à participação da invenção de al go novo, em contraposição à economia de mercado globalizada, que se impunha de forma autoritária a partir das economias centrais e de suas entidades representativas. Robert Kurz era um autor de orientação marxista, a mesma que, como dissemos, tem animado o movimento desde muito cedo, em um misto com

${ }^{26}$ Robert Kurz. A estupidez do neoliberalismo. Op. cit., p. 3. 
uma mística religiosa, dificultando a assimilação exata de seu teor. U ma coisa fica muito clara, no entanto: o capitalismo é injusto e precisa ser superado.

Nos demais números a luta ideológica continuaria acirrada. Durante a campanha para o plebiscito da Alca (Á rea de Livre Comércio das A méricas), que aconteceu em setembro de 2002, a batalha foi ferrenha. 0 número 224, de outubro deste ano, trazia na sua capa: "Plebiscito Nacional: dez milhões reprovam a Alca". Na mesma capa, outra chamada: "O modelo econômico neoliberal expulsou mais de 5 milhões de pessoas do campo." No corpo dessa matéria, podia-se ler que isso havia ocorrido entre 1999 e 2001 De acordo com o JST:

Elas foram tangidas das suas terras e dos seus sonhos pelo latifúndio cruel. Essa espécie de peste criada pelo capitalismo fez com que, para não morrer, o povo fosse para as cidades - moinhos de gente e esperanças - incorporando-se à geografia da fome e do subemprego, estatística dos sem-nomes, sem-lugares, sem-terras. ${ }^{27}$

A relação para o movimento, portanto está feita: capitalismo contemporâneo, neoliberalismo, latifúndio/agronegócio, exclusão. É nesse sentido que percebemos que a luta do MST tinha, necessariamente, que extrapolar o espaço agrário para resultar, se tudo desse certo, na conquista do espaço no campo. Não é possível a consolidação da Reforma A grária como esses sujeitos a entendem dentro do modelo então vigente. Existem instituições, como a OMC, o FMI, o Banco Mundial, e um mentor geral, os Estados Unidos. É o império do capital tentando dispersar seus tentáculos em todo o globo. 0 interessante é que o Banco Mundial, no período entre 1997 e 2002, havia tentado direcionar, inclusive, o processo de R eforma A grária em países como o Brasil, por meio da alternativa denominada "Reforma Agráría assistida pelo mercado", a RAAM. Dentro dos anos citados isso aconteceu em um projeto piloto denominado Célula da Terra, e a partir de 2003 teve continuidade por meio do Programa Nacional de Crédito Fundiário ${ }^{28}$. De acordo com João Márcio Mendes Pereira e Sérgio Sauer, além

\footnotetext{
27 TEIXEIRA, Gerson. Mais de 5 milhões de pessoas expulsas do campo em 3 anos. Jornal Sem Terra, n. ${ }^{\circ}$ 224. Out./2002. p. 4.

28 PEREIRA, João Márcio Mendes \& SAUER, Sérgio. A “reforma agrária assistida pelo mercado" do Banco Mundial no Brasil: dimensões políticas, implantação e resultados. Revista Sociedade e Estado, n. ${ }^{\circ} 3$, Set./Dez./2011, p. 587.
} 
de expressão clara de uma política governamental baseada na lógica demercado (lei da oferta e da procura por terras), tais programas explicitam embatesde longa data entre o poder político central (Executivo Federal) e setoresorganizados da sociedade brasileira. Malgrado o discurso do Banco Mundial emprol da promoção do "protagonismo social" e do "empoderamento dos pobres",os enfrentamentos em torno desses programas expressam um descompassoentre as reivindicações históricas pelo acesso à terra e a natureza da políticasocial para o campo, posta em prática pelos governos federais nas últimas décadas,centrada no "aliviamento da pobreza"29

Estamos acompanhando, desde o surgimento do MST, a luta do movimento, inclusive com uma busca constante de formação ideológica dos seus membros, no sentido de estabelecer no campo brasileiro relações diferentes daquelas encontradas na sociedade capitalista. A Reforma A grária, em seu sentido profundo, teria em última instância esse sentido. No entanto, demonstrando uma distância entre as aspirações dos movimentos e as práticas adotadas pelas entidades governamentais, mesmo nos casos mais recentes de governos pretensamente mais à esquerda, o que se realiza no momento é uma tentativa de alteração da estrutura fundiária nacional seguindo a lógica do próprio mercado. Os autores afirmam que, no discurso, tais iniciativas deveriam significar a tomada de algum tipo de poder pelas camadas da população que necessitam da terra, ainda que fosse econômico. A inda assim, não é essa a leitura que se faz dos resultados.

O motivo pareceser bem simples: dentro das relações demercado capitalistas não há solidariedade, que é a palavra de ordem repetida pelo MST, desde a infância dos seus participantes, na busca de geração do sentimento, e nas organizações internacionais, como a V ia Campesina, como também sinalizamos ao longo deste trabalho. $\mathrm{N}$ ão há respeito às especificidades por parte do capital, que se globaliza e, onde quer que chegue, insiste simplesmente em se multiplicar mais e mais. $N$ ão se pode exigir dele que se adeque a este "barroquíssimo tapete de incontáveis fios e múltiplos teares", tal como nos apresentou Bartra. Se a lógica neoliberal ingressa no campo, a dinâmica deve ser mesmo essa, da competitividade, da produtividade, da funcionalidade, e não da autonomia, da liberdade, da solidariedade.

Já vimos acima que os governos petistas não demonstraram grandes diferenças, de acordo com o próprio MST, se comparados ao de Fernando H enrique Cardoso, no que se refere à condução econômica do país. Ocorreram, é claro,

29 Idem, ibidem, p. 588. 
alterações significativas como fusões de alguns programas anteriores ou mesmo extinção de outros, em função de irregularidades constatadas em seu funcionamento. Em geral, no entanto, as linhas de crédito para a negociação, dentro de uma dinâmica do mercado, e não de desapropriação para Reforma A grária, continuaram existindo, unificadas com o nome de Programa $\mathrm{N}$ acional de Crédito Fundiário (PNCF).A avaliação de Pereira e Sauer sobre tal relação é a seguinte:

O governo Lula manteve 0 discurso que negava a continuidade entre o PNCF e os programas anteriores do governo FHC, 0 que o colocava em contradição com os documentos do próprio Banco Mundial. Por outro lado, não procede 0 discurso oficial de que 0 PNCF não concorre com os recursos públicos destinados ao programa de "reforma agrária". É verdade que o Fundo de Terras se constitui em uma fonte distinta, mas também são recursos públicos, previstos no Orçamento Geral da União. A demais, as famílias "são parte integrante da Reforma Agrária e têm, como os beneficiários dos demais programas, acesso às políticas de financiamento e de apoio previstos nos programas do MDA. 30

Já tínhamos visto que, guardadas as devidas proporções, não havia nenhum entusiasmo do MST com relação às gestões petistas depois que elas mostraram a que vieram. 0 próprio Stédile, em suas declarações, declarava a autonomia do movimento, que incomodava aqueles que gostariam de se aproximar mais do Estado para atingir seus benefícios, mas não tão completa a ponto de satisfazer os membros mais radicalmente à esquerda. Os números da Reforma A grária têm piorado e, quando a gestão Dilma foi avaliada, foi colocada como a pior nesse quesito em 20 anos, isto é, pior que o desempenho do próprio governo Fernando Henrique Cardoso. Desse modo, o que passou a ocorrer a partir do momento em que essetipo de financiamento foi incorporado às políticas agrárias foi que se estabeleceu um misto entre Reforma A grária constitucional e aquela assistida pelo mercado, que em nenhum momento foi bem avaliada pelo MST, por não representar uma ruptura com a lógica do latifúndio mas, ao contrário, premiar a especulação imobiliária no campo, e por não gerar, como resultado, a emancipação real dos participantes dos projetos, por carregar em si a lógica da competitividade e da funcionalidade fria do mercado.

30 Idem, ibidem, p. 604. 
É desse modo que compreendemos a adesão à bandeira da antiglobalização, ou o assumir por si essa causa, como um desenvolvimento natural de quem lutava por circunstâncias novas no campo. Não há democracia sem terra. Ela não existe, também, se no espaço agrário passam a ser estabelecidas pura e simplesmente as dinâmicas pertinentes ao capitalismo. Ou seja, o movimento pensa em uma sociedadedemocrática no seu sentido social, enão meramenteformal.A democracia apenas "de direito" tem permitido a proliferação das mais catastróficas desigual dades sociais no planeta.

A luta do movimento é pela consolidação de uma sociedade mais democrática nas relações humanas e econômicas, extrapolando as possiblidades do capitalismo, enfim, uma democracia de direito e de fato. Por isso, a necessidade de se contrapor ao império, ao neoliberalismo, com potencial para se ligar à rede que luta por estas mesmas causas, se comunicando e interagindo com esses outros sujeitos de forma cada vez mais eficiente. Para isso, a sociedade teria que se configurar em rede, e o movimento teria, também, que trilhar por esse caminho. 